\title{
Вплив засобів кондиційного тренування з плавання на стан системи зовнішнього дихання студентів
}

\author{
УдК: 796.013.3:797.212

\section{Є. А. Захаріна, Н. В. Глущенко}

Класичний приватний університет (м. Запоріжжя)

\begin{abstract}
Резюме. Мета роботи - проаналізувати особливості динаміки показників зовнішнього дихання юнаків під впливом занять з плавання під час кондиційного тренування. Методи дослідження. У роботі узагальнено результати обстеження 50 студентів чоловічої статі віком 19-20 років основної медичної групи. Показники зовнішнього дихання обстежуваних реєстрували за допомогою мікропроцесорного портативного спірографа СМП-21/01«Р-Д». У результаті проведених досліджень встановлено, що у студентів експериментальної групи було виявлено достовірно вищі, ніж у контрольній групі, темпи приросту більшості показників зовнішнього дихання і, навпаки, зниження частоти дихання. Висновки. Ці зміни характеризувалися впровадженням у план і структуру експериментальної тренувальної програми гіпоксичних тренувальних серій.
\end{abstract}

Ключові слова: дихальна система, студенти, плавання, кондиційне тренування.

Резюме. Цель работы - проанализировать особенности динамики показателей внешнего дыхания юношей под влиянием занятий по плаванию во время кондиционной тренировки. Методы исследования. В работе обобщены результаты обследования 50 студентов мужского пола в возрасте 19-20 лет основной медицинской группы. Показатели внешнего дыхания испытуемых регистрировали с помощью микропроцессорного портативного спирографа СМП-21/01-«Р-Д». В результате проведенных исследований установлено, что у студентов экспериментальной группы было выявлено достоверно более высокие, чем в контрольной группе, темпы прироста большинства показателей внешнего дыхания и, наоборот, снижение частоты дыхания. Выводы. Данные изменения характеризовались внедрением в план и структуру экспериментальной тренировочной программы гипоксических тренировочных серий. Ключевые слова: дыхательная система, студенты, плавание, кондиционные тренировки.

Abstract. Objective of work - analysis of the dynamics peculiarities of external breathing indices of young boys under the influence of swimming sessions during conditioning training. Methods of studies. The paper summarizes the results of examining 50 male students aged 19-20 years of basic medical group. Indices of external breathing of subjects were recorded by means of a portable microprocessor spirograph SMP-21/01 «P-D». The students of the experimental group was found to have significantly higher increase of most external breathing indices as compared to those of the control group, and, conversely, decreased respiratory rate. Conclusions. These changes were due to introduction of hypoxic training series in the plan and structure of experimental training program. Keywords: respiratory system, students, swimming, conditioning training.

Вступ. На сьогодні значно зросла кількість людей із різних верств населення, які бажають поліпшити фрізичний стан за допомогою оздоровчого плавання. Під час плавання дихання входить до частини складної координаційної структури рухів, завдяки якій досягається 
оптимальна техніка дихання 3 мінімальними енерговитратами на самодихання, що, в свою чергу, покращує результат на дистанції та поліпшує технічну та фрізичну підготовленість тих, хто займається спортивним і кондиційним плаванням. Оздоровчий або кондиційний напрямок тренування висуває низку вимог щодо грамотного підходу та вибору тренувальної програми відповідно до фрізіологічних процесів, які відбуваються в організмі плавців [4]. Відсутність знань, навичок і вміння контролювати власний рівень фрізичного навантаження призводить до негативних наслідків і відсутності позитивного результату. Одним з аспектів, який значно впливає на фрункціональну та рухову підготовленість людини, є взаємозв'язок фрізичного навантаження та адаптованої до нього дихальної системи організму. Якісне покращення та корекція дихальної системи зумовлені роботою в аеробному режимі $[2,3,5]$.

На думку багатьох фрахівців у галузі фрізичної культури і спорту, досить перспективним може бути впровадження у систему занять з фрізичного виховання студентів засобів кондиційного тренування, зокрема плавання, яке поєднує в собі елементи оздоровчого та спортивного тренування з урахуванням зон потужності, режимів роботи (аеробний, анаеробний, змішаний аеробно-анаеробний, гліколітичний, алактатногліколітичний), техніко-тактичної підготовленості та самоконтролю за розвитком функціонального стану, фрізичної підготовленості та загальною реакцією організму на фрізичне навантаження [1, 4, 7-9].

Попри численні дані про благотворну дію водного середовища на організм людини [1, 6, 8], до цього часу недостатньо розроблені питання регламентації рухової активності студентів на заняттях 3 фрізичного виховання та визначення нормативних параметрів занять оздоровчим плаванням у навчальному процесі.

У зв'язку з цим важливим $€$ контроль за змінами показників зовнішнього дихання студентів під впливом кондиційних занять з плавання.

Зв'язок роботи 3 науковими програмами, планами, темами. Робота виконана відповідно до плану НДР Класичного приватного університету на 2013-2018 рр. з теми «Проблеми та перспективи розвитку фрізичного виховання і спорту осіб різного віку» (номер держреєстрації 0113U000729).

Мета роботи - проаналізувати особливості динаміки показників зовнішнього дихання юнаків під впливом занять з плавання під час кондиційного тренування.
Методи та організація дослідження. У ході дослідження, яке тривало з вересня 2014 р. по березень 2015 р., було проведено обстеження 50 студентів чоловічої статі Класичного приватного університету (м. Запоріжжя) у віці 19-20 років, які за станом здоров'я належали до основної медичної групи. Обстежуваний контингент було поділено на контрольну групу (КГ, 27 юнаків), яка займалася на заняттях з фрізичного виховання плаванням за традиційною програмою, та експериментальну групу (ЕГ, 23 юнаки), які займались у рамках занять з фрізичного виховання за запропонованою нами експериментальною програмою 3 кондиційного тренування 3 плавання. На початку експерименту ми перевірили можливості використання розробленої нами програми кондиційних занять з плавання з метою підвищення рівня фрізичного стану студентів вищих навчальних закладів. На цьому етапі враховувався поточний рівень стану дихальної системи організму юнаків, на основі чого будувалися загальна структура i зміст поетапних тренувальних програм 3 плавання. Наприкінці експерименту ми мали змогу отримати та проаналізувати динаміку змін у дихальній системи студентів обох груп.

Під час обстеження у всіх студентів, які брали участь у дослідженні, реєстрували такі показники: життєву ємність легенів (ЖЄЛ, мл), частоту дихання (ЧД, n·хв $\left.{ }^{-1}\right)$, дихальний об’єм (ДО, л), хвилинний об'єм дихання (ХОД, л“хв $\left.{ }^{-1}\right)$, час затримки дихання на вдиху (Твд, с) та видиху (Твид, с) у стані відносного спокою; максимальну вентиляцію легенів (МВЛ, л'хв ${ }^{-1}$ ), резервні об'єми вдиху (РОвд, л) та видиху (РОвид, л). У всіх обстежуваних за допомогою стандартного сухого спірометра визначали величини життєвої ємності легенів (ЖЕЛ, л), часу затримки дихання на вдиху (Твд, с) та часу затримки дихання на видиху (Твид, с), оцінювали ступінь стійкості організму до умов гіпоксії та розраховували індекс гіпоксії (ІГ, ум. од.). Величини ЧД, ДО, ХОД, МВЛ, РОвд, РОвид і пікової об'ємної швидкості видиху (ПОШ, л“с ${ }^{-1}$ ) реєстрували за допомогою мікропроцесорного портативного спірографра СМП-21/01-«Р-Д».

Результати дослідження та їх обговорення. Завдання та наукова новизна розробленої нами експериментальної програми з кондиційного тренування з плавання студентів у процесі фрізичного виховання у вищому навчальному закладі полягає в розширенні та деталізації змісту процесу плавальної підготовки з метою адаптації та подальшої готовності фрункціонального стану організму та фрізичної підготовленості студентів до повноцінного кондиційного тренування з плавання. 
Ефрективність і зміст запропонованої нами тренувальної програми напряму залежали від реалізації таких завдань: дотримання принципів тренування; поглибленої корекції техніки плавання; корекції дихальної системи організму та оптимальної частоти дихання; оптимізації кількості рухових циклів (гребків); розвитку координаційних здібностей; тактики рівномірного проходження дистанції; спеціального силового тренування на суші та у воді; розвитку гнучкості; підвищення спеціальної витривалості на середніх і довгих дистанціях; розвитку швидкості за рахунок поступового збільшення об'єму роботи у IV та V зонах потужності, які належать до гліколітично-анаеробного та змішаного алактатногліколітичного режимів роботи, та самоконтролю за фуннціональним станом організму та фрізичною підготовленістю тих, хто займається.

Неконтрольований процес дихання під час плавання призводить до порушення обтічного та горизонтального положення тіла у воді, що, в свою чергу, порушує техніку та темп плавання та зумовлює зайве напруження м'язів, а отже, прискорює процес стомлення. Для запобігання технічним помилкам і сприяння більш якісному фрункціонуванню дихальної системи організму ми включили гіпоксичні тренувальні серії у план та структуру експериментальної тренувальної програми з перших ії тижнів.

Наводимо приклади тренувальних серій, які ми застосовували в експериментальній тренувальній програмі:

$n$ серій $\times 75$ м (25 м вдих на кожний третій гребок +25 м вдих на кожен п'ятий гребок +25 м вдих на кожний сьомий гребок);

5 м вдих на кожний третій гребок +30 с відпочинок +50 м вдих на кожний п'ятий гребок +30 с відпочинок +25 м вдих на кожний сьомий гребок; $n$ серій $\times 75$ м (25 м вдих на кожний сьомий гребок +25 м вдих на кожний п'ятий гребок +25 м вдих на кожний третій гребок);

600 м (100 м вдих на кожний третій гребок +50 м вдих на кожний п'ятий гребок) + інтервал відпочинку 30-60 с +300 м (75 м вдих на кожний третій гребок +50 м вдих на кожний п'ятий гребок +25 м вдих на кожний сьомий гребок) + інтервал відпочинку 30-60 с + 150 м (50 м вдих на кожний третій гребок +25 м вдих на кожний дев'ятий гребок);

$n$ серій $\times 300$ м (75 м вдих на кожний п'ятий гребок +25 м вільним стилем повільно +50 м вдих на кожний сьомий гребок +50 м вільним стилем повільно +25 м вдих на кожний дев'ятий гребок + 75 м вільним стилем повільно);

$n$ серій $\times 250$ м (100 м вдих на кожний третій гребок +75 м вдих на кожний п'ятий гребок +50 м вдих на кожний сьомий гребок +25 м вдих на кожний дев'ятий гребок).

У разі збільшення вентиляції легенів значно зростає робота, яка витрачається на повітрообмін, та збільшується хвилинний об'єм дихання. Важливу роль у покращенні функціонування дихальної системи відіграє аеробна здатність плавця, яка характеризується підтримкою довготривалої м'язової активності за рахунок посилення окиснювальних процесів у тканинах. Вона залежить від злагодженості різних фуункціональних систем організму, які пов'язані з надходженням кисню через систему зовнішнього дихання, транспортування кров'ю та утилізацією кисню в мітохондріях працюючих м'язів.

У результаті проведених досліджень ми встановили, що на початку формуючого експерименту реєструвалися відповідні фрізіологічній нормі значення ЖЕЛ, ДО, ЧД, РОвд і Твд (табл. 1). Водночас у юнаків обох груп відзначали знижені показники Твид, МВЛ, РОвид і ПОШ.

\begin{tabular}{|c|c|c|c|c|}
\hline Показник & $\begin{array}{c}\text { Контрольна група } \\
(\mathrm{n}=27)\end{array}$ & $\begin{array}{c}\text { Експериментальна } \\
\text { група }(n=23)\end{array}$ & $\mathbf{t}$ & $\mathbf{p}$ \\
\hline ЖєЛ, л & $4,05 \pm 0,12$ & $3,84 \pm 0,12$ & 1,22 & $p>0,05$ \\
\hline ДО, мл & $0,64 \pm 0,04$ & $0,63 \pm 0,02$ & 0,22 & $p>0,05$ \\
\hline ЧД, $n \cdot x^{-1}$ & $15,38 \pm 0,52$ & $15,03 \pm 0,33$ & 0,57 & $p>0,05$ \\
\hline МОД, л·Хв & $9,12 \pm 0,58$ & $9,46 \pm 0,31$ & 0,52 & $p>0,05$ \\
\hline Твд, с & $88,24 \pm 2,41$ & $91,26 \pm 2,54$ & 0,86 & $p>0,05$ \\
\hline Твид, с & $42,12 \pm 1,65$ & $43,57 \pm 1,56$ & 0,64 & $p>0,05$ \\
\hline ІГ, ум. од. & $0,77 \pm 0,03$ & $0,79 \pm 0,03$ & 0,47 & $p>0,05$ \\
\hline 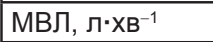 & $149,39 \pm 5,11$ & $144,09 \pm 6,13$ & 0,66 & $p>0,05$ \\
\hline РОвд, л & $1,83 \pm 0,11$ & $1,90 \pm 0,12$ & 0,42 & $p>0,05$ \\
\hline РОвид, л & $1,31 \pm 0,12$ & $1,24 \pm 0,13$ & 0,37 & $p>0,05$ \\
\hline ПОШ, л·с $\mathrm{c}^{-1}$ & $7,59 \pm 0,27$ & $7,33 \pm 0,35$ & 0,58 & $p>0,05$ \\
\hline
\end{tabular}

ТАБЛИЦЯ 1 - Показники системи зовнішнього дихання юнаків 19-20 років контрольної і експериментальної груп до проведення експерименту $(\bar{X} \pm \mathrm{m})$ 


\begin{tabular}{|c|c|c|c|c|}
\hline Показник & $\begin{array}{c}\text { Контрольна група } \\
(\mathbf{n}=27)\end{array}$ & $\begin{array}{c}\text { Експериментальна } \\
\text { група }(\mathrm{n}=23)\end{array}$ & $\mathrm{t}$ & p \\
\hline жєЛ, л & $4,82 \pm 0,15$ & $5,48 \pm 0,17$ & 2,92 & $p<0,01$ \\
\hline ДО, мл & $0,74 \pm 0,02$ & $0,83 \pm 0,02$ & 2,70 & $p<0,01$ \\
\hline ЧД, $n \cdot x^{-1}$ & $12,91 \pm 0,38$ & $11,95 \pm 0,55$ & 1,43 & $p>0,05$ \\
\hline ХОД, л $\times$ Хв $^{-1}$ & $9,37 \pm 0,38$ & $9,78 \pm 0,45$ & 0,70 & $p>0,05$ \\
\hline Твд, с & $101,55 \pm 2,53$ & $111,24 \pm 3,10$ & 2,42 & $p<0,05$ \\
\hline Твид, с & $50,88 \pm 1,77$ & $56,42 \pm 2,02$ & 2,06 & $p<0,05$ \\
\hline ІГ, ум. од. & $0,75 \pm 0,03$ & $0,81 \pm 0,03$ & 1,38 & $p>0,05$ \\
\hline 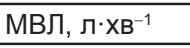 & $170,11 \pm 5,82$ & $193,19 \pm 8,22$ & 2,29 & $p<0,05$ \\
\hline РОвд, л & $1,91 \pm 0,11$ & $2,40 \pm 0,15$ & 2,62 & $p<0,01$ \\
\hline РОвид, л & $1,55 \pm 0,14$ & $1,59 \pm 0,17$ & 0,18 & $p>0,05$ \\
\hline ПОШ, л·с $\mathrm{c}^{-1}$ & $8,81 \pm 0,31$ & $9,47 \pm 0,45$ & 1,22 & $p>0,05$ \\
\hline
\end{tabular}

ТАБЛИЦЯ 2 - Показники системи зовнішнього дихання юнаків контрольної та експериментальної груп наприкінці експерименту $(\bar{X} \pm \mathbf{m})$
У цілому отримані на початку фрормуючого експерименту результати свідчили про відносну однорідність представників контрольної та експериментальної груп, що має велике значення для об'єктивної інтерпретації даних дослідження. Наприкінці дослідження для юнаків, які займалися плаванням за авторською програмою кондиційного тренування з плавання, були характерні достовірно і значно більш оптимальні показники фрункціонування дихальної системи організму порівняно з представниками контрольної групи.

Наприкінці формуючого експерименту (табл. 2) у студентів віком 19-20 років, які займалися протягом року за авторською програмою кондиційного тренування з плавання, відзначалося достовірне зростання величин життєвої ємності легенів, дихального об'єму, часу затримки дихання на вдиху та на видиху, резервного об'єму вдиху, максимальної вентиляції легенів і пікової об'ємної швидкості видиху.

Статистично значущих міжгрупових розходжень у величинах інших показників дихальної системи організму зареєстровано не було.

Після завершення формуючого експерименту для студентів експериментальної групи були характерні достовірно вищі, ніж у контрольній групі, темпи приросту життєвої ємності легенів (відповідно 42,72 $\pm 1,74 \%$ і 19,01 $\pm 1,60 \%$ ), дихального об'єму $(14,20 \pm 1,52 \%$ і $15,63 \pm 1,16 \%)$, хвилинного об'єму дихання $(21,05 \pm 1,57 \%$ і $6,04 \pm 1,20 \%)$, часу затримки дихання на вдиxy $(21,90 \pm 1,58 \%$ і $15,08 \pm 1,45 \%)$ і видиху $(29,48 \pm 1,64 \%$ і $20,80 \pm 1,47 \%)$, резервних об'ємів вдиху $(26,65 \pm 1,61 \%$ і $14,37 \pm 1,41 \%)$ і видиху $(27,79 \pm 1,62 \%$ і $18,32 \pm 1,55 \%)$, максимальної вентиляції легенів $(34,08 \pm 1,67 \%$ і $13,87 \pm 1,52 \%$ ), пікової об'ємної швидкості видиху $(29,14 \pm 1,63 \%$ і 16,07 $\pm 1,52 \%)$, індексу гіпоксії $(20,05 \pm 1,33 \%$ і 10,22 $\pm 1,45 \%)$ i,

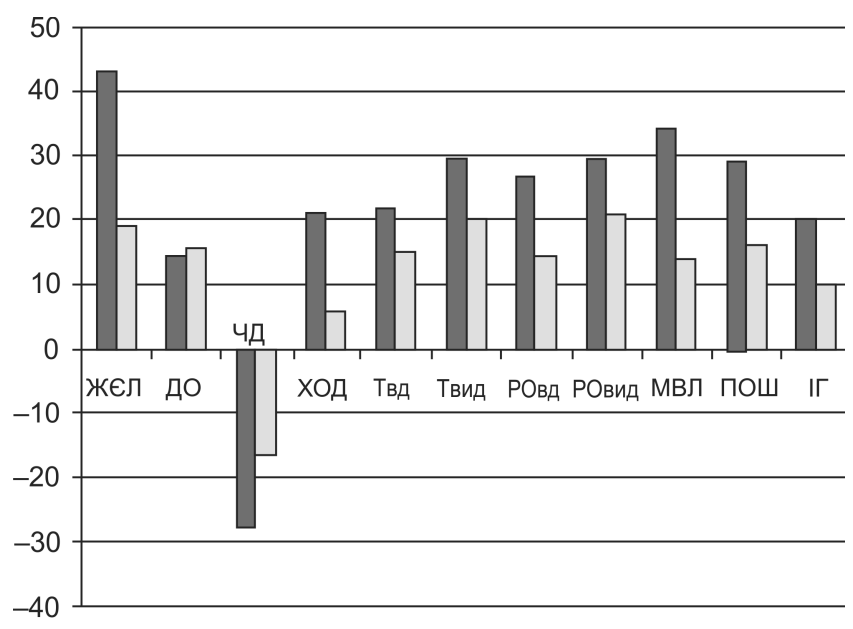

Рисунок 1 - Зміни показників системи зовнішнього дихання юнаків контрольної та експериментальної груп після завершення формуючого експерименту (у відсотках до вихідних значень):

- у контрольній групі; $\square$ - в експериментальній групі

навпаки, зниження частоти дихання (відповідно $-27,75 \pm 1,23 \%$ i $-16,06 \pm 1,24 \%$ ) (рис. 1).

Висновки. Розроблена нами програма кондиційних занять з плавання будувалася з урахуванням поточного рівня стану дихальної системи організму юнаків. Наприкінці експерименту ми мали змогу отримати та проаналізувати динаміку змін у дихальній системі студентів обох груп. Серед студентів експериментальної групи наприкінці формуючого експерименту було зареєстровано більш виражені зміни, ніж у представників контрольної групи: вищі величини життєвої ємності легенів (відповідно на 12,88 $\pm 1,95 \%$ і на $13,79 \pm 1,52 \%$ ), дихального об'єму (на $40,72 \pm 1,28 \%$ і на 12,04 $\pm 1,40 \%$ ), максимальної вентиляції легенів (на $12,67 \pm 1,97 \%$ і на $13,57 \pm 1,73 \%)$, часу затримки дихання на вдиху (на $15,59 \pm 1,54 \%$ і на $9,54 \pm 1,58 \%$ ) і видиху (на $13,79 \pm 1,60 \%$ і на 10,88 $\pm 1,52 \%$ ). 


\section{Література}

1. Булгакова Н. Ж. Оздоровительное, лечебное и адаптивное плавание : учеб. пособие для студ. высш. учеб. заведений / Н. Ж. Булгакова, С. Н. Морозов, О. И. Попов и др. ; под ред. Н. Ж. Булгаковой. - М. : Академия, 2005. - 432 с.

2. Ванюшин Ю. С. Взаимосвязь сердечно-сосудистой и дыхательной систем как инновационный способ оценки функциональных возможностей организма спортсменов / Ю. С. Ванюшин, М. Ю. Ванюшин // Теория и практика физ. культуры : Тренер : журнал в журнале. - 2009. № 10. - С. 68.

3. ДьякоВа Е. Ю. Внедрение комплексной методики обучения плаванию студентов с различными заболеваниями / Е. Ю. Дьякова, А. А. Миронов // Теория и практика физ. культуры. - 2015. - № 7. - С. 42-45.

4. ИВащенко Л. Я. Программирование занятий оздоровительным фитнессом / Л. Я. Иващенко, А. Л. Благий, Ю. А. Усачев. - К. : Наук. світ, 2008. - 198 с.

5. КамалоВа Э. И. Эфрфективность интервальной гипоксической тренировки в подготовке мужской сборной пловцов-ветеранов / Э. И. Камалова, 3. М. Кузнецова, А. В. Рыженков // Теория и практика фииз. культуры. 2008. - № 10. - С. 89-92.

6. Пильненький В. В. Організаційно-методичні основи оздоровчого тренування студентів з низьким рівнем соматичного здоров'я : автореф. дис. на здобуття наук. ступеня канд. наук з фріз. виховання і спорту : спец. 24.00.02 / В. В. Пильненький. - Львів, 2005. - 20 с.

7. Шкребтий Ю. М. Направления совершенствования методики спортивной тренировки на этапе подготовки к высшим достижениям / Ю. М. Шкребтий // Физическое воспитание студентов творческих специальностей. - X., 2005. - № 2. - C. 37-44.

8. Hines E. Fitness Swimming - 2nd ed. / E. Hines // Human Kinetics. - 2008. - 232 p.

9. Manley N. The EDGE: The Swimmer's Every Day Guide to Excellence / N. Manley, Dr. A. Goldberg, B. Steele, D. Denniston // CreateSpace. - 2009. - Vol. 1. - 102 p. zaxarina@rambler.ru

\section{References}

1. Bulgakova N. J., Morozov S. N., Popov O. I. (2005) Recreational, therapeutic and adaptive swimming : high school textbook. M.: Academy (in Russian)

2. Vanyushin Y. S., Vanyushin M. Y. (2009) The relationship of the cardiovascular and respiratory systems as an innovative way to evaluate the functionality of the body athletes. Theorya nd Practice of Physical Culture: Coach: A journal in journal, no 10, p. 68. (in Russian)

3. Dyakov E. Y., Mironov A. A. (2015) Implementation of the integrated method of swimming training of students with various diseases. Theory and Practice of Physical Culture, no 7, pp. 42-45. (in Russian)

4. Ivashchenko L. Y., BLagiy A. L., Usachev Y. A. (2008) Programming training health and fitness. K. (in Russian)

5. Kamalova E. I., Kuznetsova Z. M., Rizhenkov A. V. (2008) The effectiveness of intermittent hypoxic training in the preparation of the men's team of veteran swimmers. Theory and Practice of Physical Culture, no 10, pp. 89-92. (in Russian)

6. Pilnenky V. V. (2005) Organizational and methodological foundations of health training students with low levels of physical health ( $\mathrm{PhD}$ Thesis), Lviv (in Ukrainian)

7. Shkrebty Y. M. (2005) Directions of perfection of a technique of sports training in preparation for the highest achievements. Physical training of students of creative specialties, no 2, pp. 37-44. (in Russian)

8. Hines E. (2008) Fitness Swimming. 2nd ed. Human Kinetics.

9. Manley N., Goldberg Dr. A., Steele B., Denniston D. (2009) The EDGE: The Swimmer's Every Day Guide to Excellence. CreateSpace. 